\title{
Pediatric tectal plate gliomas: clinical and radiological progression, MR imaging characteristics, and management of hydrocephalus
}

\author{
Clinical article
}

\author{
Christoph J. Griessenauer, M.D., ${ }^{1}$ Elias Rizk, M.D. , ${ }^{2}$ Joseph H. Miller, M.D., ${ }^{1}$ \\ Philipp Hendrix, ${ }^{1}$ R. Shane Tubbs, Ph.D., ${ }^{2}$ Mark S. Dias, M.D. ${ }^{3}$ \\ Kelsie Riemenschneider, B.S., ${ }^{4}$ And Joshua J. Chern, M.D., Ph.D. ${ }^{4}$
}

${ }^{1}$ Division of Neurosurgery, Department of Surgery, University of Alabama, Birmingham; ${ }^{2}$ Pediatric Neurosurgery, Children's of Alabama, Birmingham, Alabama; ${ }^{3}$ Pediatric Neurosurgery, Penn State Milton S. Hershey Medical Center, Hershey, Pennsylvania; and ${ }^{4}$ Pediatric Neurosurgery, Children's Healthcare of Atlanta, Georgia

Object. Tectal plate gliomas are generally low-grade astrocytomas with favorable prognosis, and observation of the lesion and management of hydrocephalus remain the mainstay of treatment.

Methods. A cohort of patients with tectal plate gliomas at 2 academic institutions was retrospectively reviewed.

Results. Forty-four patients with a mean age of 10.2 years who harbored tectal plate gliomas were included in the study. The mean clinical and radiological follow-up was $7.6 \pm 3.3$ years (median 7.9 years, range 1.5-14.7 years) and $6.5 \pm 3.1$ years (median 6.5 years, range 1.1-14.7 years), respectively. The most frequent intervention was CSF diversion $(81.8 \%$ of patients) followed by biopsy $(11.4 \%)$, radiotherapy $(4.5 \%)$, chemotherapy $(4.5 \%)$, and resection (2.3\%). On MR imaging tectal plate gliomas most commonly showed T1-weighted isointensity (71.4\%), T2-weighted hyperintensity $(88.1 \%)$, and rarely enhanced (19\%). The initial mean volume was $1.6 \pm 2.2 \mathrm{~cm}^{3}$ and it increased to $2.0 \pm 4.4 \mathrm{~cm}^{3}(\mathrm{p}=0.628)$ at the last follow-up. Frontal and occipital horn ratio (FOHR) and third ventricular width statistically decreased over time ( $\mathrm{p}<0.001$ and $\mathrm{p}<0.05$, respectively).

Conclusions. The authors' results support existing evidence that tectal plate gliomas frequently follow a benign clinical and radiographic course and rarely require any intervention beyond management of associated hydrocephalus.

(http://thejns.org/doi/abs/10.3171/2013.9.PEDS13347)

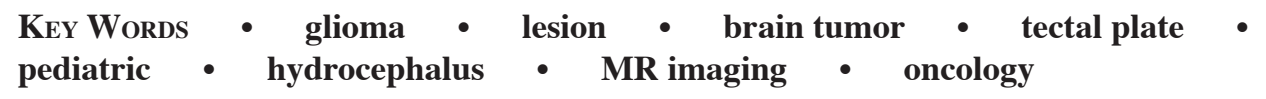

$\mathrm{B}$ RAINSTEM gliomas account for $10 \%-20 \%$ of pediatric primary brain tumors. Tectal plate gliomas are a subgroup of focal brainstem gliomas that typically present with obstructive hydrocephalus secondary to enlargement of the tectal plate and obstruction of the cerebral aqueduct. Patients frequently have a long-standing history of headaches. Additional symptoms include visual abnormalities such as Parinaud syndrome and oculomotor palsy, balance problems, and nausea and vomiting. .11, $16,22^{-10}$ Several case series have reported on the long-term outcome of tectal plate gliomas. ${ }^{1,2,5,10,11,13-15}$ Tectal plate gliomas are generally low-grade astrocytomas with a favorable prognosis. Treatment includes observation of the lesion, management of hydrocephalus, and, in selected

\footnotetext{
Abbreviations used in this paper: ETV = endoscopic third ventriculostomy; FOHR = frontal and occipital horn ratio; NF1 = neurofibromatosis Type 1 .
}

cases, biopsy of the tumor. ${ }^{4}$ Resection, radiotherapy, and chemotherapy have been generally reserved for progressive disease. ${ }^{1}$ Here, we present a group of patients with tectal plate gliomas managed at 2 academic institutions, with emphasis on clinical and radiological progression, MRI characteristics, and management of hydrocephalus.

\section{Methods}

Following approval from separate institutional review boards, hospital records and institutional databases were queried for patients with tectal plate gliomas at 2 academic institutions: Children's Healthcare of Atlanta and Children's of Alabama. The diagnosis of a tectal plate glioma was based on MRI findings at the time of diagnosis. ${ }^{3}$ Data available included age, sex, presenting symptoms, clinical and radiological follow-up, and management of the disease. Radiological measurement for tumor volume was 


\section{J. Griessenauer et al.}

defined as the product of the largest dimensions in all 3 dimensions divided by 2 at the time of diagnosis and at the last follow-up imaging study and is reported in cubic centimeters. Frontal and occipital horn ratio (FOHR) and third ventricular width were measured on axial imaging and were reported in millimeters at the same time points. Frontal and occipital horn ratio is a linear measure that has been shown to correlate well with ventricular volume and is simple to obtain. ${ }^{12}$ Statistical analysis was performed using commercially available software (SPSS version 21, IBM SPSS) to perform the Shapiro-Wilk test, paired and unpaired Student t-tests, Wilcoxon test, Mann-Whitney Utest, and ANOVA with Bonferroni and Scheffé post hoc analysis, where appropriate.

\section{Results}

\section{Patient Characteristics}

A total of 44 patients (27 males and 17 females) with tectal plate gliomas, evaluated between 1995 and 2012, were included in this study (Table 1). Age at the time of diagnosis ranged between 2 and 19 years old, with a mean age of $10.2 \pm 4.3$ years. Seven patients $(15.9 \%)$ had a history of neurofibromatosis Type 1 (NF1; 4 males and 3 females). The most common presenting symptom was headache in 22 patients $(50 \%)$. In one-quarter of patients, the tectal plate glioma was found incidentally. The mean clinical and radiological follow-up was $7.6 \pm 3.3$ years (median 7.9 years, range $1.5-14.7$ years) and $6.5 \pm 3.1$ years (median 6.5 years, range 1.1-14.7 years), respectively. Cerebrospinal fluid diversion was performed in 36 patients $(81.8 \%)$. Four patients $(9.1 \%)$ underwent biopsy of the lesion. In 2 of these patients the pathology was consistent with pilocytic astrocytoma, and in the other 2 patients the tissue was nondiagnostic. Of the patients with pilocytic astrocytoma, one patient with a history of NF1 underwent chemotherapy at another institution. The other patient underwent endoscopic biopsy of a tumor with a large cystic component and was treated with Gamma Knife surgery that was complicated by mesencephalic hemorrhage months later, resulting in cranial nerve deficits, right hemiparesis, and rubral tremor that gradually improved. One patient underwent resection, subsequent re-resection of an enlarging residual tumor, and radiotherapy after the patient presented with tumor enlargement and progressive symptoms 5 years after initial diagnosis. Pathology was consistent with pilocytic astrocytoma (Fig. 1). One patient without a history of neurofibromatosis underwent chemoand radiotherapy without prior biopsy. At last follow-up all patients in this series were alive without significant neurological sequelae (Figs. 2 and 3).

\section{Imaging Characteristics}

On radiological examination, tectal plate gliomas most commonly showed T1-weighted isointensity (71.4\%) and T2-weighted hyperintensity ( $88.1 \%)$. However, in approximately $30 \%$ of the cases, the T1-weighted images were either hyperintense $(14.3 \%)$ or hypointense $(14.3 \%)$. Gadolinium-enhanced MRI revealed enhancement in only $19 \%$ of the cases. The majority of the lesions neither enhanced $(81 \%)$ nor showed cystic components $(88.1 \%)$.
TABLE 1: Patient characteristics

\begin{tabular}{lc}
\hline \multicolumn{1}{c}{ Variable } & Value $^{*}$ \\
\hline no. of patients & 44 \\
male/female & $27: 17$ \\
mean age at presentation in yrs & $10.2 \pm 4.3$ \\
no. w/ NF1 & $7(15.9)$ \\
presenting symptoms & \\
headache & $22(50)$ \\
visual complaints & $6(13.6)$ \\
balance problems \& ataxia & $6(13.6)$ \\
nausea \& vomiting & $5(11.4)$ \\
cognitive changes & $3(6.8)$ \\
urinary complaints & $1(2.3)$ \\
numbness & $1(2.3)$ \\
symptoms unknown & $6(13.6)$ \\
incidental finding & $11(25)$ \\
mean follow-up in yrs & \\
clinical & $7.6 \pm 3.3$ \\
radiographic & $6.5 \pm 3.1$ \\
treatment & \\
CSF diversion & $36(81.8)$ \\
biopsy & $4(9.1)$ \\
resection & $1(2.3)$ \\
radiotherapy & $3(6.8)$ \\
chemotherapy & $2(4.5)$ \\
\hline
\end{tabular}

* Mean values are presented as the mean \pm SD. Other values are number of patients (\%).

Imaging characteristics were unavailable in 2 patients (Table 2).

\section{Tumor Volume}

The mean volume at presentation and last follow-up was $1.6 \pm 2.2$ and $2.0 \pm 4.4 \mathrm{~cm}^{3}$, respectively $(\mathrm{p}=0.628)$. One patient did not have imaging follow-up and another underwent resection of the tumor. Both were excluded from statistical analysis. Patients without neurofibromatosis had a significantly larger final tumor volume than neurofibromatosis patients $(\mathrm{p}<0.01)$. Of the tumors that decreased or increased, the volume change was significant ( $\mathrm{p}<0.001$ and $\mathrm{p}<0.01$, respectively) and the final tumor volume was significantly greater in patients with tumor increase than in patients with tumor decrease $(\mathrm{p}<0.05)$. The initial tumor volume was not significantly different between tumors that increased and tumors that decreased in size over time. None of the other variables in Table 3 had any effect on tumor volume.

\section{Management of Hydrocephalus}

Thirty-six patients were treated with CSF diversion, 18 with endoscopic third ventriculostomy (ETV) (42.9\%) and 16 with shunt placement (38.1\%). The type of CSF diversion was at the discretion of the treating neurosurgeon. One patient had a failed ETV followed by shunting and 

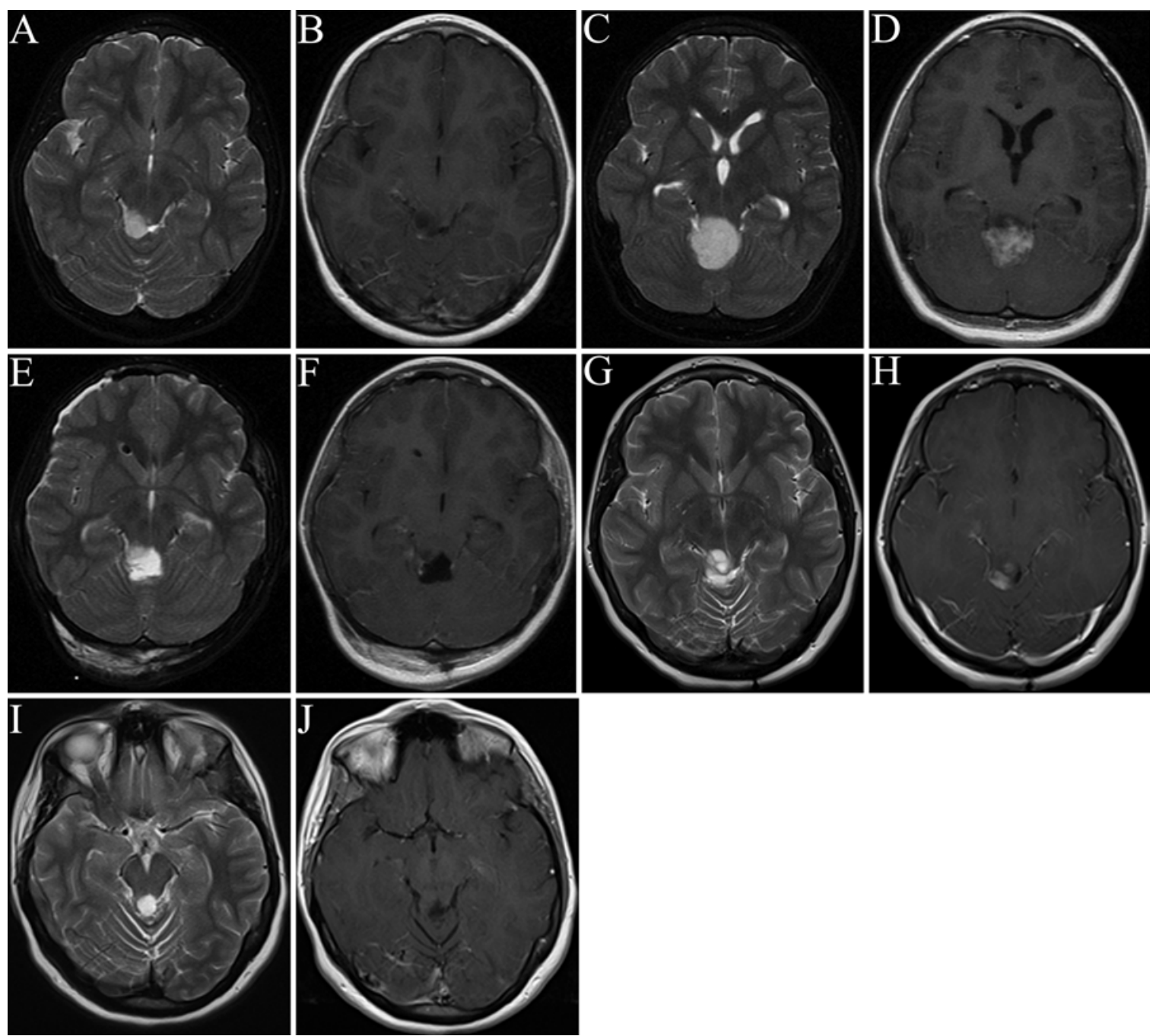

FIG. 1. Magnetic resonance images obtained in a 7-year-old girl diagnosed with tectal plate glioma (T2-weighted image [A] and T1-weighted image with contrast [B]) treated with ETV for CSF diversion. Five years later the patient underwent resection for an enlarging tumor that showed enhancement and was associated with progressive symptoms (T2-weighted image [C] and T1-weighted image with contrast [D]) and gross-total resection was achieved (T2-weighted image [E] and T1-weighted image with contrast [F]). Pathology was consistent with pilocytic astrocytoma. Three years later the tumor recurred, was re-resected, and was treated with radiotherapy (T2-weighted image [G] and T1-weighted image with contrast $[\mathrm{H}])$. Five years later there is no sign of recurrence (T2-weighted image [I] and T1-weighted image with contrast [J]).

one patient underwent shunting followed by successful ETV. Both were excluded from statistical analysis. Eight patients did not receive any CSF diversion (Table 4).

All patients had a decrease in their FOHR $(\mathrm{p}<0.001)$. Specifically, patients with CSF diversion and the subset of patients who underwent ETV had a significant decrease in FOHR $(p<0.001)$. The lack of significant decrease in FOHR in shunt-treated patients $(\mathrm{p}=0.388)$ can potentially be explained by the fact that 11 of the 15 patients underwent initial imaging after shunt placement. In regard to symptoms, patients with headache had a higher FOHR compared with patients without it $(\mathrm{p}<0.01)$.

Regarding third ventricular width, all patients had a decrease $(\mathrm{p}<0.05)$. Specifically, patients who underwent CSF diversion and the subset of patients who underwent ETV had a decrease in width $(\mathrm{p}<0.01$ and $\mathrm{p}<0.05$, re- spectively). Patients who underwent ETV had a larger initial third ventricular width than shunt-treated patients $(\mathrm{p}<$ 0.05). Again, since preoperative imaging was unavailable in 11 of 15 patients who underwent shunting, no decrease was found in that subgroup and may be explained by the aforementioned reasons. Patients with headache had a greater initial third ventricular width than patients without headache $(\mathrm{p}<0.05)$.

\section{Discussion}

Tectal plate gliomas represent approximately $5 \%$ of pediatric brainstem gliomas, ${ }^{4}$ and, unlike diffuse pontine gliomas, have a more favorable prognosis and remain clinically and radiologically stable for years after CSF diversion. ${ }^{4,7,8,13}$ Magnetic resonance imaging demonstrates a 


\section{J. Griessenauer et al.}
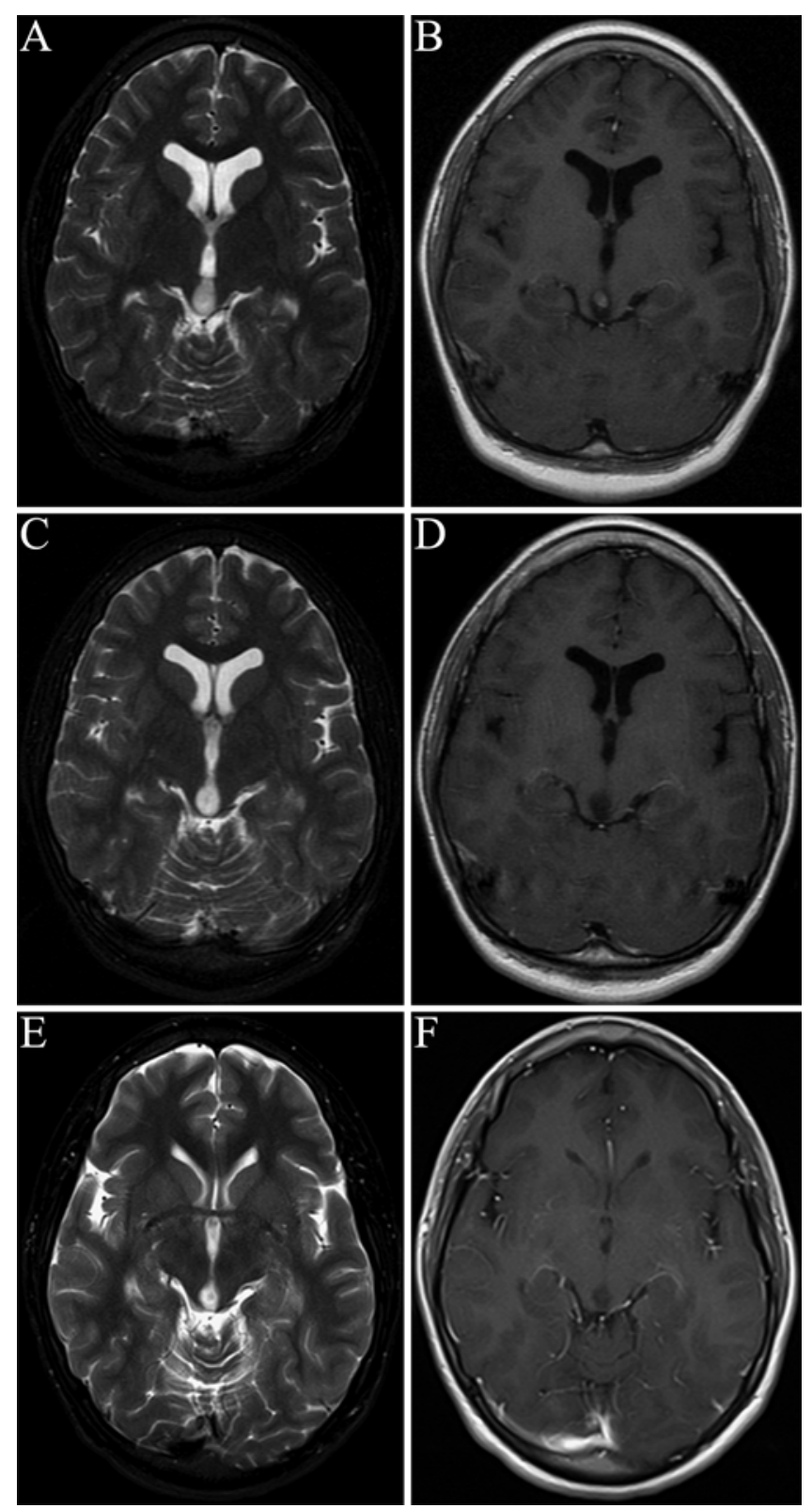

FIG. 2. Magnetic resonance images obtained in a 12-year-old girl diagnosed with tectal plate glioma (T2-weighted image [A] and T1-weighted image with contrast [B]) treated with ETV. The subtle enhancement on the initial imaging had disappeared at 3-year (T2-weighted image $[\mathrm{C}]$ and T1-weighted image with contrast [D]) and 10-year (T2-weighted image $[E]$ and T1-weighted image with contrast [F]) follow-up imaging, and the mass remained stable in volume without additional treatment.

focal, well-circumscribed, bulbous lesion deforming the quadrigeminal plate above the cerebral aqueduct that may have a posterior exophytic component that extends beyond the tectal plate. ${ }^{3,4}$ The histopathology is commonly benign and includes nonneoplastic hamartoma ${ }^{11,21}$ as well as lowgrade astrocytomas such pilocytic ${ }^{2,14,16}$ and nonpilocytic astrocytomas, $5,14,20,22$ mixed gliomas, ${ }^{14}$ and rarely more aggressive tumors such as anaplastic astrocytomas. ${ }^{14}$ In one study of tectal plate lesions that were resected for radiological progression, pilocytic astrocytoma was the most
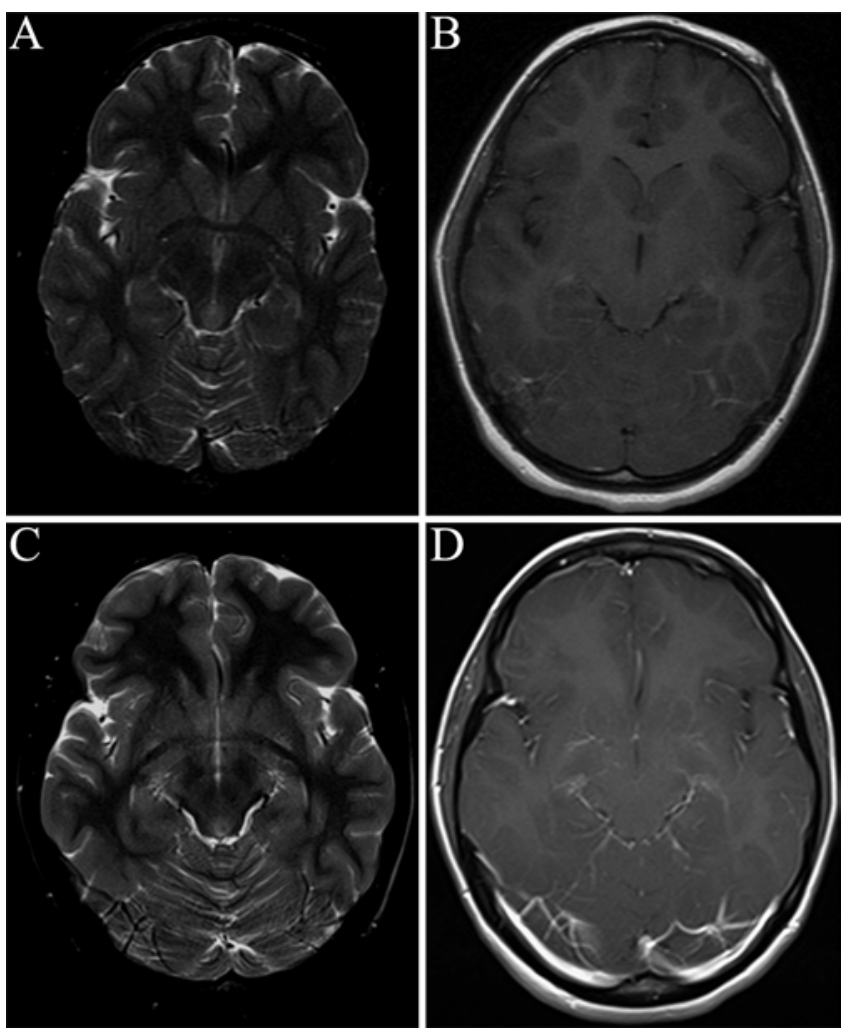

FIG. 3. Magnetic resonance images obtained in an 8-year-old girl diagnosed with tectal plate glioma treated with ETV. On imaging the mass appeared hyperintense on a T2-weighted image (A) and isointense on a T1-weighted image without contrast enhancement (B). Volume and imaging characteristics were unchanged at the 10-year follow-up (T2weighted image $[\mathrm{C}]$ and T1-weighted image with contrast [D]).

frequent pathology (36\%) followed by fibrillary astrocytoma (21\%), oligoastrocytoma (14\%), ganglioglioma (7\%), and high-grade astrocytoma $(7 \%){ }^{21}$

Tectal plate gliomas typically behave in a benign and

TABLE 2: Magnetic resonance imaging characteristics*

\begin{tabular}{cc}
\hline Variable & No. of Patients (\%) \\
\hline T1-weighted images & $30(71.4)$ \\
isointense & $6(14.3)$ \\
hyperintense & $6(14.3)$ \\
hypointense & \\
T2-weighted images & $5(11.9)$ \\
isointense & $37(88.1)$ \\
hyperintense & $0(0.0)$ \\
hypointense & \\
Gd enhancement & $8(19)$ \\
present & $34(81)$ \\
absent & \\
cystic components & $5(11.9)$ \\
present & $37(88.1)$ \\
absent &
\end{tabular}

* Imaging characteristics were unavailable in 2 patients. 


\section{Tectal plate glioma}

TABLE 3: Tumor volume*

\begin{tabular}{|c|c|c|}
\hline Variable & Mean \pm SD & p Value \\
\hline overall tumor vol $(n=42)$ & & 0.628 \\
\hline initial vol & $1.6 \pm 2.2$ & \\
\hline final vol & $2.0 \pm 4.4$ & \\
\hline \multicolumn{3}{|l|}{ tumor progression over time $(n=42)$} \\
\hline decreased in vol $(n=19)$ & & $<0.001$ \\
\hline initial vol & $1.9 \pm 2.3$ & \\
\hline final vol & $0.8 \pm 0.8$ & \\
\hline remained unchanged in vol $(n=9)$ & & NA \\
\hline initial vol & $0.8 \pm 1.0$ & \\
\hline final vol & $0.8 \pm 1.0$ & \\
\hline increased in vol $(n=14)$ & & $<0.01$ \\
\hline initial vol & $1.8 \pm 2.5$ & \\
\hline final vol & $4.4 \pm 7.1$ & \\
\hline \multicolumn{3}{|c|}{ patient characteristics, symptoms, \& tumor vol $(n=42)$} \\
\hline male $(n=26)$ & & 0.411 \\
\hline initial vol & $1.6 \pm 2.0$ & \\
\hline final vol & $2.3 \pm 5.3$ & \\
\hline female $(n=16)$ & & 0.753 \\
\hline initial vol & $1.7 \pm 2.3$ & \\
\hline final vol & $1.5 \pm 2.5$ & \\
\hline $\mathrm{HA}(\mathrm{n}=22)$ & & 0.744 \\
\hline initial vol & $1.4 \pm 2.0$ & \\
\hline final vol & $1.5 \pm 2.3$ & \\
\hline no $H A(n=20)$ & & 0.307 \\
\hline initial vol & $1.9 \pm 2.3$ & \\
\hline final vol & $2.6 \pm 6.0$ & \\
\hline $\mathrm{NF1}(\mathrm{n}=7)$ & & 0.185 \\
\hline initial vol & $0.6 \pm 0.7$ & \\
\hline final vol & $0.2 \pm 0.2$ & \\
\hline no NF1 ( $n=35)$ & & 0.802 \\
\hline initial vol & $1.9 \pm 2.3$ & \\
\hline final vol & $2.4 \pm 4.8$ & \\
\hline incidental $(n=10)$ & & 0.713 \\
\hline initial vol & $2.3 \pm 3.1$ & \\
\hline final vol & $1.1 \pm 1.2$ & \\
\hline nonincidental $(n=32)$ & & 0.713 \\
\hline initial vol & $1.4 \pm 1.8$ & \\
\hline final vol & $2.3 \pm 5.0$ & \\
\hline age at diagnosis $<10$ yrs $(n=20)$ & & 0.156 \\
\hline initial vol & $1.7 \pm 2.4$ & \\
\hline final vol & $2.3 \pm 6.0$ & \\
\hline age at diagnosis $\geq 10$ yrs $(n=22)$ & & 0.586 \\
\hline initial vol & $1.6 \pm 2.0$ & \\
\hline final vol & $1.8 \pm 2.4$ & \\
\hline \multicolumn{3}{|c|}{ imaging characteristics \& tumor vol $(n=40) \dagger$} \\
\hline T1 hyperintense $(n=6)$ & & 0.116 \\
\hline initial vol & $3.4 \pm 3.5$ & \\
\hline final vol & $1.5 \pm 0.8$ & \\
\hline
\end{tabular}

(continued) 


\section{J. Griessenauer et al.}

TABLE 3: Tumor volume* (continued)

\begin{tabular}{|c|c|c|}
\hline Variable & Mean \pm SD & $p$ Value \\
\hline \multicolumn{3}{|c|}{ imaging characteristics \& tumor vol $(n=40) \dagger$ (continued) } \\
\hline T1 isointense $(n=28)$ & & 0.940 \\
\hline initial vol & $1.4 \pm 1.9$ & \\
\hline final vol & $2.3 \pm 5.3$ & \\
\hline T1 hypointense $(n=6)$ & & 0.360 \\
\hline initial vol & $1.2 \pm 1.2$ & \\
\hline final vol & $1.7 \pm 2.1$ & \\
\hline T2 hyperintense $(n=35)$ & & 0.737 \\
\hline initial vol & $1.6 \pm 2.3$ & \\
\hline final vol & $2.1 \pm 4.8$ & \\
\hline T2 isointense $(n=5)$ & & 0.589 \\
\hline initial vol & $1.9 \pm 1.2$ & \\
\hline final vol & $1.7 \pm 1.4$ & \\
\hline enhancement $(n=8)$ & & 0.237 \\
\hline initial vol & $2.6 \pm 3.4$ & \\
\hline final vol & $1.5 \pm 1.1$ & \\
\hline no enhancement $(n=32)$ & & 0.841 \\
\hline initial vol & $1.4 \pm 1.8$ & \\
\hline final vol & $2.2 \pm 5.0$ & \\
\hline cystic $(n=4)$ & & 0.233 \\
\hline initial vol & $4.6 \pm 4.0$ & \\
\hline final vol & $1.7 \pm 1.4$ & \\
\hline not cystic $(n=36)$ & & 0.885 \\
\hline initial vol & $1.3 \pm 1.7$ & \\
\hline final vol & $2.1 \pm 4.8$ & \\
\hline
\end{tabular}

* One patient underwent tumor resection, and initial imaging was unavailable in another patient. Tumor volume is in cubic centimeters. $\mathrm{HA}=$ headache; $\mathrm{NA}=$ not applicable.

$\dagger$ Imaging characteristics were unavailable in 2 patients.

indolent fashion, and only a small number will exhibit progression, result in new neurological symptoms, and require treatment including surgery, radiation therapy, and chemotherapy. ${ }^{2,5,13-15,20-22}$ The challenge in the management of tectal plate gliomas remains in the uncertainty of knowing which tumors will eventually exhibit clinically significant growth. In our study, 44 patients diagnosed with tectal plate glioma on MRI underwent follow-up clinically and radiologically for a mean of 7.6 years and 6.5 years, respectively. Only a minority of patients required intervention aside from CSF diversion. There was no significant increase in tumor volume during the time of radiological follow-up overall. Patients without neurofibromatosis had a significantly larger final tumor volume compared with neurofibromatosis patients, indicating an even more benign course in these patients..$^{19}$ Furthermore, the increase in tumor volume was significant in patients who experienced tumor growth, but there was no significant difference in initial tumor volume between patients with and without tumor growth. Thus, initial tumor volume did not appear to be a predictor of future tumor growth.

Other studies have associated certain imaging charac- teristics including contrast enhancement or cystic changes with radiographic progression and found a correlation of tumor volume at presentation with tumor enlargement. Ternier et al. found that tumor volume at referral was around $11 \mathrm{~cm}^{3}$ in patients who underwent resection compared with around $2 \mathrm{~cm}^{3}$ in those who did not. ${ }^{21}$ The mean tumor volume in their study was larger than $5 \mathrm{~cm}^{3}$, considerably larger than in our study, which is likely the explanation for the higher rate of resection (35\%) compared with our study. Patients treated conservatively had tumor volume comparable to our study patients, which is also more in line with tumor volumes reported by others., ${ }^{1,3,22}$ The significance of radiological progression is controversial, as progression without concurrent development of clinical symptoms has been observed in a large number of patients with tectal plate gliomas. ${ }^{1}$

In regard to imaging characteristics, our study confirms the findings of others that tectal plate gliomas are frequently isointense on T1-weighted images, hyperintense on T2-weighted images, and have a low rate of contrast enhancement. ${ }^{3,421}$ None of these imaging features was predictive of tumor enlargement in our study.

Due to the indolent nature of tectal plate gliomas in 
Tectal plate glioma

TABLE 4: CSF diversion and ventricular size

\begin{tabular}{|c|c|c|}
\hline Variable & Value & p Value \\
\hline \multicolumn{3}{|l|}{ type of CSF diversion $(n=34)^{\star}$} \\
\hline ETV & $18(42.9 \%)$ & \\
\hline shunt & $16(38.1 \%)$ & \\
\hline \multicolumn{3}{|l|}{ mean FOHR } \\
\hline total $(n=41)^{*} \dagger$ & & $<0.001$ \\
\hline initial FOHR & $0.43 \pm 0.09$ & \\
\hline final FOHR & $0.39 \pm 0.06$ & \\
\hline CSF diversion $(n=33)^{\star} \ddagger$ & & $<0.001$ \\
\hline initial FOHR & $0.43 \pm 0.09$ & \\
\hline final FOHR & $0.39 \pm 0.07$ & \\
\hline ETV only $(n=18)^{*}$ & & $<0.001$ \\
\hline initial FOHR & $0.49 \pm 0.09$ & \\
\hline final FOHR & $0.42 \pm 0.07$ & \\
\hline shunt only $(n=15)^{\star} \ddagger$ & & 0.388 \\
\hline initial FOHR & $0.37 \pm 0.04$ & \\
\hline final FOHR & $0.35 \pm 0.03$ & \\
\hline no CSF diversion $(n=8)$ & & 0.199 \\
\hline initial FOHR & $0.39 \pm 0.06$ & \\
\hline final FOHR & $0.41 \pm 0.05$ & \\
\hline \multicolumn{3}{|c|}{ mean 3rd ventricular width in $\mathrm{mm}$} \\
\hline total $(n=38)^{*}+\S$ & & $<0.05$ \\
\hline initial width & $7.9 \pm 6.0$ & \\
\hline final width & $6.6 \pm 4.4$ & \\
\hline CSF diversion $(n=30)^{\star} \ddagger$ & & $<0.01$ \\
\hline initial FOHR & $8.2 \pm 6.3$ & \\
\hline final FOHR & $6.3 \pm 4.3$ & \\
\hline $\operatorname{ETV}(n=15)^{*}$ & & $<0.05$ \\
\hline initial width & $11.1 \pm 7.2$ & \\
\hline final width & $8.4 \pm 5.2$ & \\
\hline shunt $(n=15)^{\star} \ddagger$ & & 0.249 \\
\hline initial width & $5.3 \pm 3.5$ & \\
\hline final width & $4.2 \pm 1.4$ & \\
\hline no CSF diversion $(\mathrm{n}=8)$ & & 0.378 \\
\hline initial width & $6.9 \pm 5.2$ & \\
\hline final width & $7.6 \pm 4.7$ & \\
\hline
\end{tabular}

* One patient had a failed ETV followed by shunting and 1 patient had a shunt followed by a successful ETV. Both patients were excluded here. $\dagger$ In 1 patient initial imaging was unavailable.

$\ddagger$ The initial FOHR measurement was obtained in 11 patients after the shunt procedure.

$\S$ Third ventricular width was unavailable in 4 patients ( 3 patients who underwent ETV and 1 patient who underwent shunting followed by successful ETV).

the majority of cases, treatment of hydrocephalus is the mainstay of surgical treatment. Endoscopic third ventriculostomy has proven to be an effective method of CSF diversion $^{17,23}$ and allows for biopsy of the tumor or even partial resection in selected cases. ${ }^{4}$ Long-term ETV success rates for this entity of greater than $70 \%$ up to around $90 \%$ have been reported. ${ }^{6,9,18}$ In our study CSF diversion resulted in a significant decrease in ventricular volume and third ventricular width. The inability to demonstrate an effect on ventricular size in patients who underwent shunt treatment was explained by the lack of available preoperative imaging in a large portion of those patients. This is in line with the observation that the most significant reduction in ventricular size in patients with tectal glioma who undergo ETV occurs early, within 1 year, with only modest reduction thereafter. ${ }^{17}$

\section{Conclusions}

The results of this study support existing evidence that tectal plate gliomas, particularly if their volume is around $2 \mathrm{~cm}^{3}$, have an indolent clinical and radiographic course and rarely require any intervention beyond management of hydrocephalus and radiological observation. Both ETV and shunting are reasonable options for CSF diversion and result in a decrease in ventricular size.

\section{Disclosure}

This work was supported through the Children's of Alabama Hydrocephalus Research Award. The authors report no conflict of interest concerning the materials or methods used in this study or the findings specified in this paper.

Author contributions to the study and manuscript preparation include the following. Conception and design: Griessenauer, Rizk, Dias, Chern. Acquisition of data: Griessenauer, Rizk, Riemenschneider, Chern. Analysis and interpretation of data: Griessenauer, Rizk, Hendrix, Chern. Drafting the article: Griessenauer, Rizk, Tubbs. Critically revising the article: all authors. Reviewed submitted version of manuscript: all authors. Approved the final version of the manuscript on behalf of all authors: Griessenauer. Statistical analysis: Griessenauer, Miller, Hendrix. Administrative/technical/material support: Griessenauer. Study supervision: Griessenauer, Chern.

\section{References}

1. Bowers DC, Georgiades C, Aronson LJ, Carson BS, Weingart JD, Wharam MD, et al: Tectal gliomas: natural history of an indolent lesion in pediatric patients. Pediatr Neurosurg 32: 24-29, 2000

2. Boydston WR, Sanford RA, Muhlbauer MS, Kun LE, Kirk E, Dohan FC Jr, et al: Gliomas of the tectum and periaqueductal region of the mesencephalon. Pediatr Neurosurg 17:234-238, 1991-1992

3. Grant GA, Avellino AM, Loeser JD, Ellenbogen RG, Berger MS, Roberts TS: Management of intrinsic gliomas of the tectal plate in children. A ten-year review. Pediatr Neurosurg 31: 170-176, 1999

4. Guillamo JS, Doz F, Delattre JY: Brain stem gliomas. Curr Opin Neurol 14:711-715, 2001

5. Hamilton MG, Lauryssen C, Hagen N: Focal midbrain glioma: long term survival in a cohort of 16 patients and the implications for management. Can J Neurol Sci 23:204-207, 1996

6. Hellwig D, Grotenhuis JA, Tirakotai W, Riegel T, Schulte DM, Bauer BL, et al: Endoscopic third ventriculostomy for obstructive hydrocephalus. Neurosurg Rev 28:1-38, 2005

7. Hoffman HJ, Becker L, Craven MA: A clinically and pathologically distinct group of benign brain stem gliomas. Neurosurgery 7:243-248, 1980

8. Khatib ZA, Heideman RL, Kovnar EH, Langston JA, Sanford RA, Douglas EC, et al: Predominance of pilocytic histology in dorsally exophytic brain stem tumors. Pediatr Neurosurg 20:2-10, 1994

9. Kulkarni AV, Drake JM, Mallucci CL, Sgouros S, Roth J, Con- 


\section{J. Griessenauer et al.}

stantini S, et al: Endoscopic third ventriculostomy in the treatment of childhood hydrocephalus. J Pediatr 155:254-259.e1, 2009

10. Lázaro BC, Landeiro JA: Tectal plate tumors. Arq Neuropsiquiatr 64:432-436, 2006

11. May PL, Blaser SI, Hoffman HJ, Humphreys RP, HarwoodNash DC: Benign intrinsic tectal "tumors" in children. J Neurosurg 74:867-871, 1991

12. O’Hayon BB, Drake JM, Ossip MG, Tuli S, Clarke M: Frontal and occipital horn ratio: a linear estimate of ventricular size for multiple imaging modalities in pediatric hydrocephalus. Pediatr Neurosurg 29:245-249, 1998

13. Pollack IF, Hoffman HJ, Humphreys RP, Becker L: The longterm outcome after surgical treatment of dorsally exophytic brain-stem gliomas. J Neurosurg 78:859-863, 1993

14. Pollack IF, Pang D, Albright AL: The long-term outcome in children with late-onset aqueductal stenosis resulting from benign intrinsic tectal tumors. J Neurosurg 80:681-688, 1994

15. Ramina R, Coelho Neto M, Fernandes YB, Borges G, Honorato DC, Arruda WO: Intrinsic tectal low grade astrocytomas: is surgical removal an alternative treatment? Long-term outcome of eight cases. Arq Neuropsiquiatr 63:40-45, 2005

16. Robertson PL, Muraszko KM, Brunberg JA, Axtell RA, Dauser RC, Turrisi AT: Pediatric midbrain tumors: a benign subgroup of brainstem gliomas. Pediatr Neurosurg 22:65-73, 1995

17. Romeo A, Naftel RP, Griessenauer CJ, Reed GT, Martin R, Shannon CN, et al: Long-term change in ventricular size following endoscopic third ventriculostomy for hydrocephalus due to tectal plate gliomas. Clincal article. J Neurosurg Pediatr 11:20-25, 2013
18. Sacko O, Boetto S, Lauwers-Cances V, Dupuy M, Roux FE: Endoscopic third ventriculostomy: outcome analysis in 368 procedures. Clinical article. J Neurosurg Pediatr 5:68-74, 2010

19. Schirmer CM, Goumnerova LC: Brainstem glioma, in Winn HR (ed): Youmans Neurological Surgery. Philadelphia: Saunders, 2011, Vol 2, pp 2114-2120

20. Squires LA, Allen JC, Abbott R, Epstein FJ: Focal tectal tumors: management and prognosis. Neurology 44:953-956, 1994

21. Ternier J, Wray A, Puget S, Bodaert N, Zerah M, Sainte-Rose C: Tectal plate lesions in children. J Neurosurg 104 (6 Suppl): 369-376, 2006

22. Vandertop WP, Hoffman HJ, Drake JM, Humphreys RP, Rutka JT, Amstrong DC, et al: Focal midbrain tumors in children. Neurosurgery 31:186-194, 1992

23. Wellons JC III, Tubbs RS, Banks JT, Grabb B, Blount JP, Oakes WJ, et al: Long-term control of hydrocephalus via endoscopic third ventriculostomy in children with tectal plate gliomas. Neurosurgery 51:63-68, 2002

Manuscript submitted July 6, 2013.

Accepted September 30, 2013.

Please include this information when citing this paper: published online November 1, 2013; DOI: 10.3171/2013.9.PEDS13347.

Address correspondence to: Christoph J. Griessenauer, M.D., 1530 3rd Ave. S., Birmingham, AL 35294. email: cgriessenauer@ uabmc.edu. 